\title{
Desplazamientos teóricos y metodológicos en el conocimiento de lo juvenil en lo étnico contemporáneo en México
}

Deslocamentos teóricos e metodológicos no conhecimento do juvenil no étnico contemporâneo no México

Theoretical and methodological shifting in the approach of the youth in the contemporary ethnicity in México

\section{Maritza Urteaga Castro Pozo}

\section{OpenEdition \\ Journals}

Edición electrónica

URL: http://journals.openedition.org/aa/3985

DOI: $10.4000 /$ aa.3985

ISSN: 2357-738X

Editor

Programa de Pós-Graduação em Antropologia Social (UnB)

Edición impresa

Fecha de publicación: 1 diciembre 2019

Paginación: 51-82

ISSN: 0102-4302

Referencia electrónica

Maritza Urteaga Castro Pozo, «Desplazamientos teóricos y metodológicos en el conocimiento de lo juvenil en lo étnico contemporáneo en México», Anuário Antropológico [En línea], v.44 n.2 | 2019,

Publicado el 03 diciembre 2019, consultado el 27 abril 2021. URL: http://journals.openedition.org/aa/ 3985 ; DOI: https://doi.org/10.4000/aa.3985

\section{(c) (i) (9)}

Anuário Antropológico is licensed under a Creative Commons Atribuição-Uso Não-Comercial-Proibição de realização de Obras Derivadas 4.0 International. 


\title{
Desplazamientos teóricos y metodológicos en el conocimiento de lo juvenil en lo étnico contemporáneo en México
}

\section{Theoretical and methodological shifting in the approach of the youth in the contemporary ethnicity in México}

\author{
Maritza Urteaga Castro Pozo \\ Escuela Nacional de Antropología e Historia/ ENAH - México
}

\section{Introducción}

"Jóvenes indígenas" es uno de los sujetos sociales emergentes de las grandes transformaciones socio culturales de fines del siglo XX e inicios del XXI en México. Son jóvenes de diferentes etnias del desplazamiento, partícipes principales de las grandes oleadas migratorias, de la obligatoriedad de la escuela secundaria, de la penetración de los medios de comunicación en las áreas y regiones rurales indígenas, y de las consecuencias de una de las sublevaciones sociales más importantes que inauguraron el siglo XXI, el levantamiento zapatista en Chiapas. Desde el inicio del nuevo milenio, el nuevo sujeto de indagación se fue convirtiendo en un campo de estudio que aporta a las discusiones en torno a la reconfiguración de la alteridad étnica en el siglo XXI en la antropología mexicana, y al conocimiento de los dispositivos diferenciales en los que se asienta la condición juvenil en los colectivos indígenas urbanos y rurales de México, tanto históricamente como en los actuales procesos acelerados de transformación estructural y cultural.

En este texto narro y reflexiono sobre mi experiencia investigativa construida en interlocución con los debates académicos sobre la reconfiguración de lo juvenil y de lo étnico en la contemporaneidad mexicana a partir de las consecuencias de los procesos de globalización y de neoliberalización económica y cultural y de cambio tecnológico en curso.

Inicio con la perspectiva analítica que fui construyendo y que atraviesa mi práctica investigativa sobre los jóvenes indígenas en la ciudad de México. En los dos siguientes apartados narro mi experiencia en el estudio del actor joven indígena, las perspectivas teórico metodológicas iniciales y las que posteriormente fui incorporando, cómo mis preguntas de investigación fueron cambiando y ampliando las formas de conocimiento y el conocimiento sobre las juventudes étnicas en la ciudad 
de México con cada herramienta metodológica que ponía en juego en el trabajo de campo, y cómo salían a la luz ciertos temas de los debates teóricos planteados por la antropología contemporánea en torno a la construcción de la etnicidad en procesos de desterritorialización. En la cuarta parte propongo algunos retos epistémicos que las metodologías colaborativas y horizontales nos ponen como antropólogos en y de la contemporaneidad social.

\section{Planteamiento del problema y abordaje metodológico}

La emergencia de un sujeto joven entre las etnias mexicanas en las oleadas de migración del último cuarto del siglo XX hacia las ciudades es identificada desde las investigaciones demográficas y los estudios sobre migración y antropológicos. Se caracterizan las grandes oleadas de migración de la población rural más empobrecida como parte de las transformaciones neoliberales en la política y economía del país. Si bien la migración no constituía un fenómeno nuevo entre la población rural e indígena en el siglo XX, las olas migratorias de fin de siglo tenían características particulares: las rutas (hacia las zonas agrícolas industriales, las megaciudades y ciudades en crecimiento dentro y fuera del país), los actores principales (jóvenes desde los 14 años), los objetivos y expectativas de los migrantes y la intensidad y velocidad del proceso (Pérez Ruiz, 2002a; Valencia Rojas, 2000). El censo del año 2000 revela la transformación de los patrones de asentamiento de la población indígena que de rurales tendieron hacia la urbanización. Así, uno de cada tres indígenas en el país vivía en las ciudades y seis ciudades concentraban el $43.5 \%$ de la población indígena urbana de México ${ }^{1}$. Este fenómeno se diferencia de las migraciones anteriores de los y las indígenas, más individuales y puntuales, puesto que en este caso son etnias del desplazamiento, etnias en migración, definiéndolas como "el desplazamiento territorial, orientado al cambio residencial de los grupos sociales con el fin de mejorar su calidad de vida” (Mora; Durán; Corona; Vega, 2004).

La temática étnica ha sido un tema recurrente y tradicional en la antropología mexicana, sin embargo, el tema de los jóvenes indígenas no fue central en la disciplina hasta inicios del siglo XXI, cuando diversos estudios señalan la formación y reconocimiento dentro de las etnias mexicanas de un grupo de edad que podía homologarse a la juventud urbana (Anguiano, 2002; Feixa, 1998; García, 2003; Martínez, 2002; Meneses, 2002; Ortiz, 2002; Pacheco, 1997; Pérez Ruiz, 2002b).

$\mathrm{Al}$ indagar sobre los motivos de este desinterés, encontré dos pares de conceptos antropológicos hegemónicos en la academia, por los menos desde los años cin- 
cuenta, que fueron claves en la invisibilización de niños y jóvenes en los estudios sobre los grupos étnicos. Por un lado, el de cultura homologable a etnia - conceptuada como sistema internamente homogéneo o integrado cuyos miembros comparten patrones, valores, sistemas de creencias y significaciones que delimitan, por medio de la diferencia, sus fronteras con otras etnias y que no admite la diferencia, ni el conflicto ni la inconsistencia interna. Por otro, la díada de conceptos, socialización e instituciones socializadoras, enmarcada en una visión convencional del proceso socializador que enfatiza la transmisión de conocimientos de los adultos hacia los niños que fueron percibidos a través de la adquisición de los roles sociales de la cultura de origen. Ambas posturas provenientes del culturalismo y funcionalismo como formas de conocimiento produjeron un tipo de conocimiento sobre los niños y los jóvenes en la disciplina: como receptores pasivos o aprendices de la sociedad adulta. En otra línea de investigación antropológica rastreada en algunas etnografías de los pueblos indígenas de la misma época, los jóvenes fueron identificados en los ritos de paso o ciclos ceremoniales masculinos (eventos como el acceso al trabajo en sitios ajenos y lejanos a la unidad familiar, al "sistema de cargos" y al matrimonio) los cuales marcan las transiciones de la niñez a la adultez. Sin embargo, los principales participantes, los jóvenes, son trivializados por los investigadores en favor del "evento".

Los retos teóricos para la antropología pasaron por desplazar la mirada hacia los procesos de cambio e inconsistencia internas, los conflictos, las contradicciones y la movilidad de los sujetos étnicos contemporáneos. Rompiendo "la regla amplia del método práctico bajo las normas clásicas con las que estábamos de acuerdo de forma ambivalente, si se mueve no es cultural” (Rosaldo, 1991, p. 191), el sujeto (de estudio) móvil, jóvenes indígenas impulsa movernos más allá de los pueblos étnicos y a seguirlos en sus desplazamientos e involucramientos con múltiples instancias modernas y referentes sociales. El acceso de los jóvenes a ámbitos de los que fueron excluidos durante la modernidad del siglo XX (educación superior, mercado, consumo, ámbitos laborales y flujos tecno informacionales) es problematizado desde la antropología en los debates sobre la construcción de la identidad étnica fuera de los territorios de origen, entre indígenas sujetos a la multi-referencialidad social y cultural urbana (Anguiano, 2002; Pérez Ruiz, 2002a, 2002b).

Entre los años 1980 y 90 en la antropología mexicana, el giro hermenéutico que permitió el retorno del sujeto, la reintroducción de la praxis, el reconocimiento del punto de vista del "nativo", la inter-discursividad en la construcción del 
conocimiento antropológico, posibilitó la aceptación, entre nuevas generaciones de investigadores, de los caminos metodológicos propuestos por Appadurai (flujos culturales globales, paisajes étnicos, dislocaciones), Marcus (etnografía multisituada), Rosaldo (zonas de frontera) y otros autores para dar cuenta de las diásporas poblacionales étnicas en sus múltiples y complejos modos y contextos de desterritorialización, re-territorialización, dislocación, glocalización y entender las nuevas circunstancias sociales y culturales que hacían posible esta nueva realidad de la contemporaneidad mexicana.

En especial, los modos de construcción etnográficos propuestos por Marcus (2001) - seguir a la gente, seguir los objetos, seguir las ideas, seguir las biografías, trayectorias de vida, seguir el conflicto, entre otros - llamaron mi atención y la de otros colegas inmersos en el tema. Teníamos necesidad de conocer y comprender a los jóvenes de diversas procedencias étnicas en la ciudad. Su propuesta de etnografía multisituada no partía de un lugar o grupo delimitado, ni de teorías a priori, al contrario, fomentaba una mirada en permanente construcción y maleable para el estudio de trayectorias y conexiones identificadas en el trabajo de campo. Simultáneamente, las discusiones teóricas en torno a las estructuras de poder que silencian e invisibilizan los lugares sociales de la diferencia (Caputo, 1995) al interior de las culturas (homologables a etnias) y en las preguntas epistemológicas que se hacen desde la investigación antropológica dan paso al ingreso de las voces y visiones de niños y jóvenes en los procesos de cambio.

En el campo de estudios sobre la juventud, la problematización de "lo joven en lo indígena” tuvo que lidiar con el entonces paradigma teórico dominante construido en torno a los jóvenes de la modernidad industrializada. Un paradigma que identificó a la juventud como aquella etapa en el tramo de edad que corresponde a la educación secundaria y superior cuando se transita de la edad infantil a la adulta, refiriéndose a jóvenes urbanos de clase media y universitarios y que aludía a una moratoria social de los roles adultos, tanto en términos de deberes como de derechos. Desde esta perspectiva, los jóvenes campesinos e indígenas sin educación y en condiciones de desventaja no eran contemplados (Fernández Poncela, 2003). Idea que también era alimentada desde la antropología mexicana que consideraba que la noción de lo joven era “ajena a los indígenas porque había surgido en Europa en el siglo XVIII, producto de la modernidad y, por tanto, había sido introducida entre los indígenas por actores externos" (Pérez Ruiz, 2011, p. 70).

Si bien desde los años 1980, otro paradigma se abría paso entre los estudio- 
sos en juventud, el de una concepción sociocultural de juventud, haciendo ingresar distintos contextos socioculturales y a diversos actores - entre ellos los y las mismas jóvenes-como participantes en la conformación de los distintos modos de ser joven, las investigaciones sobre estas realidades en México se habían centrado principalmente en las urbes y con jóvenes urbanos (Urteaga, 2000). De ahí que no fuera tarea fácil visibilizar lo joven entre las etnias (entonces, predominantemente rurales) para los investigadores.

Desde la perspectiva sociocultural, a la cual me adscribo, la juventud es una fase en el ciclo de vida que cambia de forma y contenido en el tiempo y el espacio, entendiéndose que cada cultura organiza la transición de la infancia a la edad adulta con formas y contenidos variables. Las formas en que la sociedad produce y reproduce a sus nuevos miembros se dan en dos ámbitos, el aparato institucional que da vida a los jóvenes y el simbólico, esto es, las ideas que se producen sobre lo que debe ser un joven. Para que exista juventud, debe estar presente una serie de condiciones sociales (instituciones, normas comportamientos que distingan a los jóvenes de otros grupos de edad) que definan y encaucen los comportamientos distintivos y permitidos y las oportunidades vitales de los jóvenes. Y, simultáneamente, una serie de "ideas" (imágenes culturales y representaciones sociales) cargadas de valoraciones, atributos y ritos que marcan las distinciones entre los jóvenes y los otros segmentos de edad. Esta perspectiva propone a los jóvenes como actores y agentes sociales activos en la creación e intervención de la realidad. Están involucrados en la construcción de sus propias vidas, las vidas de los agentes de sus entornos más inmediatos y de las sociedades en las que viven. Admite que los jóvenes son creadores y poseedores de culturas de juventud y otorga prioridad a las prácticas y formas expresivas y simbólicas a través de las cuales la sociedad es experimentada por la gente joven. Enfatiza el presente de las experiencias relacionales de la gente joven “en sus propios términos", esto es, situarse en las prácticas y visiones que los actores jóvenes en interacción social con adultos, jóvenes, niños y ancianos construyen sobre el sí mismo y su entorno (Urteaga, 2011).

El sujeto joven indígena emerge en el momento del quiebre del modelo de desarrollo capitalista del siglo XX y de profundas transformaciones en las instituciones modernas que produjeron a los jóvenes (familia, escuela, trabajo, normas jurídicas y legislación, ejército, seguridad pública, mercado laboral, mercado de consumo, medios de comunicación, publicidad y narcotráfico) y un cambio en el sistema de referencia social. La Encuesta Nacional de Juventud del 2000 (IMJ, 2002) reveló 
contextos de inequidad y desigualdad estructural preocupantes que estrechaban fuertemente las opciones de los jóvenes mexicanos para materializar sus procesos de autonomía. La precarización y empobrecimiento profundo caracterizan la población juvenil. Los estudiosos de las juventudes con perspectivas cualitativas trasladamos las preguntas de investigación hacia la agencia juvenil, al cómo y qué es lo que los(as) jóvenes mexicanos estaban haciendo para dar salida a las consecuencias de la globalización, a las reformas del mercado y al bloqueo de los caminos modernos hacia la adultez. Cuáles eran los nuevos marcos referenciales de las juventudes, cuál era su participación en los nuevos escenarios abiertos por las transformaciones sociales y tecnológicas en curso, cuáles eran los recursos y capitales con los que enfrentaban la desafección institucional, entre otras preguntas que aportaron al debate sobre la condición juvenil contemporánea. Esto implicaba seguir a los jóvenes en sus dislocamientos y desplazamientos temporo-espaciales realizando trabajo de campo.

El estudio de los jóvenes indígenas y migrantes se gestó entre estos debates y propuestas. Me motivaba la actitud teórica de Margaret Mead (1979) quien con base en datos de campo entre los adolescentes samoanos desafía la definición de Stanley Hall (1905) sobre los mismos, como una condición universal - un estadio del desarrollo humano entre el "salvajismo" y la "civilización" que se encontraría en todas las sociedades. Mead pregunta si podían generalizarse a otras culturas los rasgos de la juventud occidental moderna, interrogante que consideré pertinente para revisar con otras lentes la entonces reciente formación y reconocimiento entre las etnias de una juventud.

\section{Primer momento: la sorpresa juvenil étnica en el espacio urbano}

La primera vez que me topé con la temática y con la realidad de jóvenes indígenas fue en la Alameda Central de la ciudad de México², entre los años 1997 y 1998, en un estudio exploratorio sobre los usos y apropiaciones juveniles de la Alameda Central que realicé con estudiantes de antropología de la UAM-Iztapalapa en el marco del Proyecto Formativo "Tiempos y espacios de ocio de los y las jóvenes de la Ciudad de México”. Enseñando herramientas metodológicas de la antropología urbana y la antropología de la juventud a estudiantes que desarrollaban sus trabajos finales de grado, realizamos una serie de recorridos por los espacios públicos de la ciudad. Uno de ellos fue la Alameda. Se trababa de identificar a los segmentos juveniles que acudían a este espacio emblemático, a través de los usos que hacían 
del mismo, la temporalidad de esas ocupaciones espaciales y sus interacciones con los adultos.

Fuimos sistemáticamente por varios meses y a distintas horas del día a la Alameda, tanto en días hábiles y como en fines de semana. Encontramos que un espacio como éste era ocupado diariamente por diferentes segmentos de la población en general, y también por jóvenes muy heterogéneos ${ }^{3}$. Además de una Guía de Observación exhaustiva, también diseñamos una pequeña encuesta a través de la cual obtuvimos información básica sobre estas poblaciones (origen, edad, género, escolaridad, ocupación, motivos de asistencia y frecuentación del espacio).

Desde el primer domingo de trabajo de campo en la Alameda fuimos desbordados por un actor juvenil que ocupaba el espacio desapareciendo a los otros segmentos etarios y a otros jóvenes de nuestra visión y de nuestros oídos. Llegamos a sentir que estábamos en “otro país” por la cantidad de lenguas que escuchábamos a nuestro alrededor. Trabajamos cada domingo en la Alameda y sus alrededores para observar el accionar de este actor en el espacio y fuimos adecuando el cuestionario incorporando pueblos de origen, lugar de habitación en la ciudad, tiempo de llegada a la misma, motivos de su migración, vinculación con sus familias parentales, espacios a los que asistían en su tiempo libre y expectativas, entre otros temas. Los resultados de la aplicación de la encuesta nos hicieron denominarlo genéricamente “jóvenes indígenas migrantes". Este último término señalaba pueblos de origen de los estados aledaños a la Ciudad de México como el Estado de México, el norte de Puebla, Hidalgo, Tlaxcala y Michoacán.

Ellos y ellas en su mayoría eran de reciente migración y estaban posicionados en los últimos escalones laborales y sociales en la ciudad, con escasa remuneración y baja calificación. En su mayoría trabajaban de albañiles, con puestos diferentes: trazadores, fierreros, carpinteros, yeseros, marmoleros, tablarroqueros, pintores, impermeabilizadores, electricistas, plomeros, aluminieros, herreros, limpiadores. También había quienes se empleaban de mozos, ayudantes de mecánica y como soldados; mientras ellas eran empleadas domésticas. Los jóvenes varones recién llegados vivían en la periferia de la ciudad, rentando una habitación o estaban alojados con familiares del mismo pueblo que llegaron mucho antes. Los migrantes de generaciones anteriores levantaron redes familiares y étnicas de apoyo para insertarse laboral y educativamente en la ciudad. Estas redes ayudaban a los varones recién llegados a encontrar empleos temporales para las empresas o para subcontratistas de la construcción o en el servicio doméstico a las mujeres. Ellos se desplazaban 
largas distancias diariamente en la ciudad tanto para encontrar trabajo como para disfrutar de su tiempo de ocio; ellas vivían en las zonas residenciales donde prestaban sus servicios.

Estaban muy vinculados a sus familias y pueblos de origen a través del envío regular de dinero y establecían contacto permanente con su entorno afectivo. Las familias, por su parte, les daban apoyo afectivo, les proporcionaban redes comunitarias y/o familiares y les enviaban productos. Algunos tenían mucho más tiempo en la ciudad y dijeron no retornar porque tenían un mayor y más continuo acceso a empleos y porque disfrutaban de su escaso tiempo libre haciendo amigos que les permitían experimentar una juventud menos acotada a la costumbre.

Una observación sistemática de sus prácticas de socialidad en estos espacios públicos reveló tensiones entre los parámetros de comportamiento social entre hombres y mujeres en la urbe y en sus pueblos de origen. Usando las clásicas herramientas antropológicas (observación y encuesta), edito algunas páginas de mi Diario de Campo para mostrar cierto relajamiento en las formas conductuales de sus culturas de origen en la intensa socialidad interétnica que encontramos en la Alameda:

El domingo, desde muy temprano y de manera abrumadora, hacen aparición jovencitas que trabajan en el servicio doméstico y jóvenes varones que trabajan como albañiles, mecánicos, mozos y soldados. Sus edades fluctúan entre los $15 \mathrm{y}$ los 25 años de edad. Este conjunto juvenil se apropia todo el día domingo de la Alameda Central de maneras muy diversas y si bien llegan en grupos pequeños o solos, rápidamente se interrelacionan de manera grupal con mucha intensidad. Una primera mirada a sus comportamientos señala algunas particularidades de su apropiación de este espacio público: temporalidad (en determinados días y horarios: el sábado por la tarde y el domingo todo el día) y copamiento (que hace desaparecer del espacio a cualquier otro grupo etario). La frecuencia con que las jóvenes mujeres visitan la Alameda no varía: siempre y cada domingo, porque es su único día libre. Mientras los varones la frecuentan algunos días de la semana por algunas horas y los domingos todo el día. Ellas llegan con sus amigas en grupos de dos o tres, mientras ellos lo hacen en grupo o solos. Los motivos de su visita son: dar la vuelta, encontrarse con los amigos, conocer amigos y porque no hay otra cosa qué hacer. Al mediodía se observa un intenso ir y venir de unos y otros en los pasillos, fuentes y bancas, y entre los puestos de ambulantes, en un afán de identificar a un candidato novio/ novia o simplemente dar la vuelta. Cuando el grupo está conformado por jovencitas y son objeto de algún piropo por parte de algún joven, ellas ríen y cuchichean entre sí. Cuando los jóvenes caminan a través 
de los pasillos bromean y se avientan entre sí. Los grupos de chavos requieren de una sola oportunidad para contactarse con algunas chavas.

Cuando termina el concierto-baile tempranero en la Alameda, organizado por SOCIOCULTUR y las autoridades de la Delegación Cuauhtémoc, una gran cantidad de chavos y chavos toma rumbo a la calle Revillagigedo. En ella se ha instalado una pista de baile, en realidad es sólo un terreno sin piso, es la Pista La Culebra. El costo de la entrada es de 12 pesos. La música que anima a la muchachada oscila entre rock discotequero, quebradita, cumbia, rock pop, tecno. El bailar brincando de la chaviza levanta polvo y las parejas danzantes están llenas de sudor y del polvillo blanco del piso de tierra. La interacción entre los y las jóvenes es amistosa. Las miradas de los chavos hacia las chavas son intensas. Las conversaciones son breves: nombre, dónde vives, a qué te dedicas, a qué hora llegaste, con quien vives. Sólo los más conocidos parecen hablar de cosas más íntimas o privadas. Los chavos se dirigen unos a otros sonriendo y exclamando “¡Ya viste esa cosita,!" mientras señalan con los ojos a alguna chava que llama su atención; algunos, más expresivos, llaman la atención de la chava con chiflidos; ellas, por su parte, sólo sonríen y algunas se sonrojan. Como a las 07:30 de la noche inicia la despedida. Nadie sale solo, todos en grupos grandes de entre tres y seis personas o en parejas y van en dirección a la estación del Metro Hidalgo. Dentro de la estación el bullicio juvenil es aumentado, la policía del metro sólo observa (Diario de Campo, 2004-2005).

La encuesta reveló su posicionamiento de recién llegados a la ciudad y su percepción de la misma como puente para conseguir sus metas inmediatas, como ganar algo de dinero, enviarlo a sus familiares, volver con sus amigos de infancia y su entorno afectivo familiar. La observación directa sistemática de sus prácticas de ocio reveló una relación más estrecha con el espacio urbano. Por ejemplo, éste no fungía solo de tránsito temporal o fuente de ocupaciones provisionales e interacciones efímeras sin apego alguno. Encontramos apropiaciones micro de los espacios urbanos frecuentados ${ }^{4}$ por estos jóvenes donde hacían "lugares", construían relaciones afectivas intensas y duraderas con jóvenes indígenas de diversos pueblos, relaciones a las que dotaban de sentido y daban sentido a su experiencia urbana. A estos espacios concurrían jóvenes solteros, así como parejas jóvenes con hijos pequeños que jugaban en los parques y deportivos. Lo que los jóvenes buscaban eran espectáculos culturales, musicales, bailables, cinematográficos, teatrales y lugares para comer y para estar entre sí. Eran prácticas urbanas y encuentros interétnicos entre jóvenes. 


\section{Segundo momento: la investigación sobre lo juvenil en lo étnico}

Desde mediados del 2004 hasta abril de 2006, llevé a cabo una indagatoria acerca de los “jóvenes indígenas migrantes" en la Ciudad de México. El estudio fue solicitado por la Dirección de Fortalecimiento de los Indígenas de la Comisión Nacional para el Desarrollo de los Pueblos Indígenas (CDI) y fue realizado en dos partes. Entre agosto 2004 y febrero de 2005, se realizó un diagnóstico situacional que incluyó: 11 entrevistas a jóvenes indígenas migrantes ( 8 hombres y 3 mujeres) originarios de diferentes etnias y partes del país (triqui, mixteca, otomí, tzeltal, zapoteca, purépecha), radicados en la zona metropolitana y con distintas ocupaciones (estudiantes, trabajadores ambulantes, estudiantes - trabajadores y profesionistas) entre los 13 y los 25 años de edad. Realicé también entrevistas a adultos migrantes y observaciones sistemáticas a las prácticas culturales y sociales de los jóvenes en espacios públicos. En abril de 2006 se lanzó una convocatoria abierta para participar en el Taller de Intercambio de Experiencias para Jóvenes Indígenas Migrantes en la Ciudad de México y participaron voluntariamente 35 jóvenes (18 mujeres y 17 hombres) de 11 etnias, predominantemente universitarios y profesionistas con una edad promedio de 22 años. Mantuve un registro etnográfico en el diario de campo y es el insumo de datos empíricos para este artículo.

La invitación a realizar este diagnóstico sobre los jóvenes indígenas me implicó un gran reto en términos de mis conocimientos y de mi formación antropológica. Se trataba de indagar cómo estos sujetos sociales emergentes articulaban su condición juvenil, étnica y migrante en la ciudad de México. El primer paso fue una inmersión en la literatura antropológica sobre el tema. Encontré estudios sobre las juventudes indígenas rurales y los que se centraban en los y las jóvenes migrantes en las ciudades. Se preguntaban: 1) por la especificidad de la juventud que se estaba formando en los grupos étnicos: a quiénes se denominaba jóvenes en diferentes etnias y por quiénes estaba compuesta esta categoría reciente; 2) por las representaciones sociales de las etnias sobre esta nueva condición etaria en el ciclo de vida de la población indígena, contrastándolas con las representaciones que las instituciones de la sociedad mexicana tenían sobre los jóvenes.

Los estudios de pueblos indígenas y ciudades con presencia indígena identificaron otras transformaciones socioculturales que, desde mi perspectiva analítica, homologué a condiciones sociales de producción de la juventud indígena. Estaban el volumen y el peso demográfico de los jóvenes en todo el país y en las etnias mexicanas (censos 1990, 2000 y 2005) ; el deterioro de las regiones rurales indígenas 
que forzaba al abandono de las actividades agrícolas y a la migración de los más jóvenes hacia las grandes ciudades y otras en crecimiento - generadoras de dinámicas económicas con mayores posibilidades de empleo y estudio. La cultura migrante reconfiguraba la vida de los jóvenes indígenas, tanto de los que migraban como de los que se quedaban: requería de nuevos acuerdos familiares y comunitarios; conducía a los jóvenes a entornos de trabajos novedosos y acarreaba nuevas adquisiciones culturales. Otro productor juvenil era la creciente influencia de los medios de comunicación (televisión y radio, con la entrada de la electrificación de las zonas indígenas) en los imaginarios y expectativas de vida de las poblaciones étnicas en zonas rurales como urbanas - en tanto portadores de repertorios de símbolos de la cultura global y juvenil (moda, música, comportamientos, rituales juveniles, etc.). Por mi parte, incluí las consecuencias del levantamiento zapatista y el reconocimiento Constitucional de México como nación multiétnica y pluricultural entre los años 1992 y 2001 como otro productor de juventud. La implementación de políticas afirmativas en las poblaciones indígenas incumbe a los jóvenes, como el acceso a la educación superior en su forma convencional (a través de porcentajes o cuotas de acceso y becas de estudio) y en su forma intercultural (construcción de universidades interculturales en las zonas indígenas).

Los estudios también identificaron nuevos actores e imágenes juveniles: el joven o la joven migrante indígena, el joven y la joven estudiante indígena (estudiantes secundarios y estudiantes universitarios), los jóvenes solteros que no migran y no estudian ("los tradicionales") y los profesionistas. Actores que emergían en todos los entramados sociales en transformación y eran objeto de representación social, esto es, de autorreconocimiento de los sujetos y reconocimiento por parte de la sociedad indígena y mestiza (García Martínez, 2003).

La literatura consultada me proporcionó ciertas líneas de indagación sobre las cuales seguir, como la pregunta por la especificidad juvenil migrante indígena en las ciudades en el marco de los nuevos contextos de dislocación de los sujetos, de su ingreso en ámbitos novedosos de educación, empleo u organización y de las reconfiguraciones étnicas y relaciones interétnicas.

\section{Abriendo una "caja de pandora" o ¿cómo acercarse a una realidad juvenil tan compleja y diversa?}

A diferencia de la mayoría de los estudios consultados, que centraban su atención en un grupo étnico en la ciudad, decidí tomar otro camino: concentrar mi aten- 
ción en jóvenes provenientes de diferentes etnias y estados del país en la ciudad de México y rastrearlos en espacios públicos, instituciones u organizaciones de reagrupamiento étnico. Teóricamente emplacé a los jóvenes en sus interacciones (adaptación, negociación, conflicto y préstamos recíprocos) con tres escenarios socioculturales de construcción de lo juvenil: la cultura hegemónica, las culturas parentales y las culturas generacionales. Trataba de explorar desde la experiencia de los y las jóvenes, quiénes eran, cómo vivían y percibían su presente, cómo lo estaban haciendo en la ciudad y sus modos de ser joven e indígena en la ciudad. Inicié el trabajo de campo retornando a los espacios públicos que había identificado en 1997, sabía que hallaría jóvenes. Empecé a contactar jóvenes con característica similares a las de ese año y poco dispuestos a ser entrevistados porque les quitaba su tiempo libre, sin embargo, con algunos(as) logré concertar citas en otros días de la semana y a algunas en sus ambientes laborales, algunas entrevistas fueron exitosas, otras no tanto, aunque logré que me contactaran con amigas(os) o primos y parientes que podrían participar de este estudio.

Usando la técnica de la bola de nieve ${ }^{7}$, fui contactando jóvenes en organizaciones indígenas en la ciudad como la Asamblea de Migrantes Indígenas en la Ciudad de México, el Diplomado Derechos Indígenas en Zonas Urbanas y Desarrollo o el Centro Interdisciplinario para el Desarrollo Social (Cides). Esta técnica fue necesaria en una megalópolis como la ciudad de México para incorporar jóvenes de diferentes etnias y clases sociales. Con cada contacto intenté citas para entrevistas más formales (tanto adultos como jóvenes), además, mantuve conversaciones informales. Con esa información incorporé en los guiones de entrevistas más preguntas sobre su condición migrante y el peso de sus culturas parentales en sus vidas en la ciudad y amplié mi campo de estudio, incorporé otras instituciones con actores que quisieran participar. Los universitarios me abrieron otro ámbito, sitios web manejados por jóvenes indígenas, donde podía encontrar ciertas revistas y textos que publicaban grupos de jóvenes estudiantes de algún lugar, manifiestos producidos por jóvenes agregados en las ciudades, o la disputa con las cifras de Censos oficiales de población indígena (decían ser más numerosos), así como eventos de poesía, de música, baile, de música, deportivos y otros de carácter intergeneracional. Descubrí en esos sitios que internet no solo servía a los jóvenes para comunicarse y encontrarse, también para educarse y conocer sobre sexo, cuidados de no embarazarse, noviazgo y otros asuntos que les preocupaban en su presente.

La complejidad y heterogeneidad de los sujetos resultaron inaprensibles en la 
categoría oficial "jóvenes indígenas migrantes”, ocultaba jóvenes de diversas etnias que arribaron a la ciudad en tiempos distintos, provenientes de clases sociales con capitales educativos, posibilidades de empleo y expectativas de vida muy diferentes. No obstante, compartían el estar activamente involucrados en la construcción de sus vidas y de sus entornos étnicos. Necesitaba otras herramientas analíticas para no caer en la dicotomía moderno/tradicional. "Zonas de frontera” (Rosaldo, 1991), como propuesta epistémica y metodológica me permitía analizar procesos de cambio e inconsistencia interna en una localidad, región o país, ingresando en la expresión de los conflictos y contradicciones que se producían en el movimiento, flujo e interacción de los actores con múltiples y novedosas situaciones.

Como investigadora estaba ubicada en espacios de intersección intercultural e intergeneracional - cultura hegemónica, culturas parentales y generacionales donde narrativas, prácticas y experiencias y saberes, se cruzaban y oponían. Los formulé como espacios interpretativos terceros - in beetween (Bhabha, 2002) -, "sitios de producción cultural creativa" (Rosaldo, 1991), que daban cuenta de las vidas de los(as) jóvenes "como experiencias de participación en la transición del ciclo de vida, más que como zonas de exclusión” (James, 1995).

El diagnóstico reveló una gran diversidad de situaciones en las vidas de los jóvenes. Los entrevistados eran estudiantes, trabajadores, estudiantes y trabajadores y profesionistas con edades entre los 13 y los 25 años. Me encontré con comerciantes ambulantes de artesanías y café, trabajadoras domésticas, albañiles, abogados y estudiantes universitarios. Provenían de etnias distintas (triqui, mixteca, otomí, tzeltal, zapoteca, purépecha), algunos llegaron siendo niños y otros ya jóvenes y los había nacidos en la ciudad de México. Había de los que provenían de etnias que habían llegado entre los años 50 y 60, y también aquellos que provenían de etnias de reciente migración (tzeltales y tzotziles de Chiapas). Algunos vivían con sus familias en los predios étnicos del centro de la ciudad, otros vivían entre citadinos (casas familiares con parientes o en las casas de familias para las que trabajaban) y otros de manera independiente. Algunos estaban "muy amarrados" a sus etnias de origen y otros se habían alejado de las mismas, aunque todos tenían vínculos con sus familias.

En las relaciones de los jóvenes con las culturas hegemónicas, la preocupación principal era el trabajo o la falta de él. Los jóvenes indígenas comparten con toda la juventud mexicana una experiencia crítica: encuentran un panorama estrecho de opciones. La diferenciación social y el tiempo de arribo generacional de los grupos étnicos a la ciudad condicionan las posibilidades de inserción laboral y producen vivencias heterogéneas. 
Ana María (tzeltal, Chiapas) tiene 29 años, cuenta solo con estudios de primaria, tiene dos hijos pequeños y su esposo está gravemente enfermo. Sebastián (tzeltal) tiene 23 años y un año viviendo en la ciudad. Ambos están intentando posicionarse y hacerse un nicho del mercado de café y artesanías chiapanecas en la ciudad, mercado que está en manos de etnias de Oaxaca, que llegaron antes y tienen vínculos con las autoridades políticas delegacionales, que les abren espacios en las ferias y otros eventos para la venta de productos regionales.

Maciel, otomí (Querétaro) de 24 años, tiene un hijo pequeño y desde hace algunos meses forma parte de la Unión de Artesanos y Trabajadores no Salariales, a través de sus familiares y paisanos ha logrado levantarse como comerciante de pan en el tianguis de Tlatlelilco ${ }^{8}$, en donde trabaja 6 horas diarias por las tardes, además se ha empleado desde muy chico como albañil (Diario de campo, 2004-2005).

A pesar del panorama descrito, la opinión de estos jóvenes coincide en que autoadscribirse como indígenas tiende a ser benéfico en la medida en que disfrutan de las redes comunitarias étnicas de influencia y apoyo, formas privilegiadas de reagrupación de los indígenas migrantes en la ciudad. Sin embargo, las redes no tienen el mismo peso en la ciudad. Uno de los jóvenes entrevistados, zapoteca de Juchitán (Oaxaca), comenta a propósito:

Me considero aquí con un estatus mayor. Los paisanos aquí tenemos redes muy fuertes y si hay un paisano que está trabajando aquí y además es influyente, le corresponde por ser nuestro paisano ayudarnos. Hay un nivel socioeconómico relativamente alto [...] Tenemos un senador, diputados, nuestra condición nos es muy favorable. Desde mi perspectiva, podría decir que no afecta ser indígena, pero ser indígena zapoteca, aclaro. Si fuera un indígena chontal, igual y si me quejaría, porque podría decir que no hay tantos paisanos; siento que es muy relativo a la etnia (Comunicación personal, 2005).

Felipe, uno de los jóvenes con quien dialogué largamente, forma parte de la primera generación de triquis que accedió a la Educación Superior, abogado con maestría en Derecho, líder juvenil fuertemente comprometido con los valores comunitarios. Incluí fragmentos del diálogo que sostuvimos el 2 de febrero de 2005 , insertando descripciones de mi Diario de Campo, donde se observa la reflexividad del sujeto.

Felipe: En la vecindad donde vivían en El Molinito ${ }^{8}$, los migrantes de nuestra 
comunidad de origen organizados, realizaban convivios y asambleas, escuchaban nuestra música y nosotros ahí estábamos, sentados o jugando y escuchábamos lo que platicaban, que era en lengua triqui y aunque no quieras te va entrando pues lo repiten tus papás, tus tíos. Nosotros estábamos bien amarrados [al pueblo triqui] a pesar del discurso de mis padres: "ustedes tienen que estudiar, salir adelante, ya no tienen que ser como nosotros". A los 14 años, fue a estudiar a Puebla entrando en contacto con una comunidad de jóvenes indígenas orgullosos de su identidad; entonces comenzó a vincularse de manera más libre con sus orígenes: "No me siento a gusto con la camisa de citadino, me gusta esto, empezamos a aprender a trabajar como ellos, en el campo, y nos empezó a gustar meternos y empezamos a reacomodarnos en lo nuestro". Tuvo que demostrar a los jóvenes triquis de la comunidad que "él no era un triqui de ciudad", reaprendiendo el idioma hasta manejarlo "como ellos", aprendiendo la historia de la comunidad, "lo que te hace regresar la mirada hacia el pueblo". Aprende sobre el "compromiso comunitario". En corto tiempo fue conocido y reconocido entre los jóvenes de Santo Domingo ${ }^{10}$ y de otras comunidades aledañas y la asamblea de su comunidad lo eligió como representante de la juventud entre los migrantes, un cargo estratégico para el reagrupamiento triqui en la ciudad. Como parte de la estrategia de reagrupamiento, forma con amigos jóvenes de la comunidad el grupo musical "Emigración Triqui": "Necesitábamos nuestra propia música y músicos” en los eventos. Hace 10 años están juntos por el compromiso comunitario basado en lealtades a las familias, a los cargos de la comunidad. "Tengo compromisos, hice compadres, voy a ser mayordomo, ya he pasado cargos, ya he estado haciendo obra pública, incluso en la ciudad, hicimos un puente vehicular ahí en la comunidad Nicolás Romero ${ }^{11}$, donde vivo con varias familias triquis. Somos 50 familias donde hay triquis, nahuatls y totonacos, tenemos una organización multicultural de ahí mismo". Está construyendo su casa a través del sistema de manos vuelta entre grupitos de compañeros jóvenes que necesitan apoyo para construir sus casas; y se hace tiempo para ir a jugar basket ball con jóvenes triquis cada domingo en el Toreo ${ }^{12}$ porque los jóvenes son un sostén importante para su comunidad (Comunicación personal, 2005).

En lo que sigue se muestran parte de las tensiones que los jóvenes profesionales triquis tienen con la falta de empleo estructural de la sociedad mexicana y sus expectativas profesionales y las de sus culturas parentales. También emergerá cómo la ciudad discrimina, obliga y relega a las mujeres indígenas - incluso aquellas que tienen educación superior y técnica - a los trabajos de servicio doméstico ${ }^{13}$.

M: ¿Las redes comunitarias ayudan a los jóvenes a acceder a un empleo?

F: El problema es que ahora hay muchos jóvenes profesionistas triquis que están 
por terminar la carrera o algunos ya la terminaron, pero están sin trabajar. Ahí choca la primera idea que tenían los triquis que llegaron migrando a la ciudad. Ahora yo soy profesionista y los primeros decían que con estudiar íbamos a resolver los problemas, íbamos a salir de la pobreza o tener mejor vida y ahora no hay trabajo para nosotros, ese es un gran problema, el trabajo. Las mujeres, por ejemplo, son las que tienen más posibilidades de conseguir un empleo aunque no esté relacionado a lo que estudiaron.

M: ¿Como cuáles?

F: Sobre todo para las compañeras en el servicio doméstico, pues difícilmente me lo dan a mí ¿no?Y a una mujer si se lo dan .

M: Pero las que han estudiado en una universidad ¿aceptan ser empleadas domésticas?

F: Aún así lo han hecho algunas, sobre todo lo hacen los sábados o los domingos, pero no lo dicen con orgullo, verdad, ni te lo dicen, tú te enteras por alguien que te lo contó, pues no creo que para un universitario sea un orgullo terminar la carrera y estar trabajando en el servicio doméstico, la verdad.

$\mathrm{M}: \mathrm{Y}$ en otros servicios ¿tampoco encuentran trabajo?

F: Si, pero ganan muy poco. En sí, si hacemos las comparaciones, una enfermera, una secretaria, gana mucho menos que una trabajadora doméstica, claro su estatus es más elevado pero gana más una trabajadora doméstica. Yo he visto que hasta las maestras que están en los kinders ganan menos que una trabajadora doméstica. Entonces, muchas dicen...pues para qué estudié tanto. Es una decepción con la que nos encontramos, nada más fue la imaginación de nuestros padres.

Ellos trabajaban en algún lado donde veían que el licenciado ganaba bien o iban donde trabajaba el ingeniero y ganaba más. Pues claro, tu hijo va a ser ingeniero, va a ser doctor, pero el hijo no tiene las redes que tiene construidas el que es abogado, el abogado tiene a su papá que es abogado y lo va a colocar; el doctor tiene a su papá o a su tío, su abuelo que es abogado y lo va a colocar y tú no tienes a nadie, tú eres hijo de un humilde campesino que desertó del campo.

M: ¿Tú estás inserto en algunas redes de abogados?

F: Sí, pero con aquellos que están identificados con la causa indígena, mi causa ¿no? Y es muy difícil porque ahí no hay campo laboral, está muy restringido. Hemos intentado también por la Universidad Nacional Autónoma de México, pues puede haber oportunidad allí, donde en diciembre terminé la Maestría. Fui becario de la Fundación Ford y creo que ese es uno de los programas que necesitamos los jóvenes, programas que tiene una beca completa para estudiantes indígenas para estudios de posgrado. El problema es que la beca dice que hay que regresar con 
ese compromiso comunitario, y allí el problema es que si te metes al medio académico y se te olvida que hay un compromiso comunitario, estamos creando académicos y no profesionistas comprometidos con lo comunitario (Comunicación personal, 2005).

Líderes como Felipe son parte de los conflictos y contradicciones producidos en el espacio fronterizo abierto entre los principios rectores de la cultura hegemónica (individualistas) y los de su cultura parental étnica (comunitarios) en un contexto de falta de empleo estructural. Felipe veía muy importante fomentar el compromiso comunitario entre los jóvenes universitarios y profesionales triquis, formados en los principios individualistas de la ciudad y en los de su formación universitaria que chocan con los compromisos colectivos y las jerarquías etarias de respeto en las que sus padres y las generaciones anteriores se socializaron. Las tensiones entre adultos y jóvenes profesionales se manifestaban a través de exigencias mutuas. Si bien los padres incentivaban y apoyaban que sus hijos estudiaran, reprobaban que los jóvenes quisieran trabajar y recibir un pago por sus servicios en los proyectos para la comunidad. Sentían una traición por parte de sus jóvenes y recelaban de "sus conocimientos de 'aquel lado'”. Los profesionales triquis no veían horizontes de trabajo ni de vida en sus pueblos de origen y tampoco en las formas de reagrupamiento de sus etnias en la ciudad. Muchos optaban por realizar colaboraciones puntuales a sus comunidades sin asumir cargos ni compromisos comunitarios y otros se separaban y asumían caminos más individualistas para lograr un mejoramiento en su calidad de vida. Felipe veía necesario generar puentes para el diálogo entre los jóvenes y los adultos y ancianos de su comunidad.

\section{El Taller: cruce de fronteras...}

En abril de 2006 continué la segunda parte de esta investigación. La CDI me pidió diseñar y convocar un "Taller de Intercambio de Experiencias para Jóvenes Indígenas Migrantes en la ciudad de México”. Realicé ese diseño teniendo como base la primera fase de esta investigación, profundizando el enfoque de la agencia como capacidad de movilizar recursos culturales, educativos, mediáticos y otros aprendizajes informales adquiridos a través de sus relaciones, que convierten en recursos y utilizan para transformar su posición y su entorno. Dirigí las preguntas sobre su condición étnica, juvenil y migrante hacia las situaciones y relaciones que experimentaban en los lugares de trabajo, educación, consumo, vivienda, uso de las tecnologías, reconfiguración étnica en la ciudad, etc., que permitieran más espacio 
a la dimensión de la improvisación (Bourdieu, 2012). Propuse el Taller con dinámicas de "grupos de discusión", una condición fundamental era que los jóvenes escogieran las mesas con tópicos diferentes dónde querían aportar y participar y que eligieran un representante de grupo para exponer las conclusiones de las discusiones.

ElTaller atrajo a 35 jóvenes (mitad mujeres, mitad hombres) en su gran mayoría estudiantes (universitarios, pero también secundarios y preparatorianos) y profesionistas jóvenes. Antropología, etnohistoria, lingüística, historia, geografía, filosofía, comunicación, música, artes plásticas, fueron las disciplinas cursadas por los estudiantes en la ciudad. Entre los profesionistas llegaron abogados, enfermeras, politólogos y administradores públicos. La mayor parte de ellos pertenecían a pueblos indígenas, pero también estuvieron presentes algunos que no se adscribieron a etnia alguna. Sus puntos de vista respecto de los temas planteados, ser joven, ser indígena y ser migrante, fueron heterogéneos.

\section{"Ser joven"}

Inicio este apartado con un fragmento del diálogo que discurrió el 4 de abril de 2006 en la Mesa "La condición juvenil de los jóvenes indígenas de la ciudad de México" del Taller de Intercambio de Experiencias para Jóvenes Indígenas Migrantes de la Ciudad de México, en el cual se discutieron algunas significaciones del ser joven en las comunidades de origen como en la ciudad.

L - mujer: La juventud, así como es definida, en primer lugar se basa en la cuestión biológica, en lo que es la pubertad y todo eso y como el Instituto Mexicano de la Juventud lo considera: a partir de los 19 años, hasta los 29; hay una edad determinante de tu vida donde eres joven. Creo que es muy relativo $[\ldots]$ sí hay una cierta etapa de tu vida donde se te identifica la libertad, la rebeldía, la creatividad, entre muchas cosas. Pasas a una cierta etapa y automáticamente ya no eres joven, porque ya tienes otras funciones, se te adjudica otro estatus. En las concepciones indígenas no existe una categoría de joven como tal pero sí se identifica ese periodo de tu vida como...

C - mujer: Un estado de soltería...

G - hombre: De donde yo soy, desde el momento en que te casas, si tienes 20 años o 15 o los que sean, ya dejas de ser joven, ya eres un adulto, eso es lo único que determina el ser señor.

C - Esto va a depender de lo que se cree que es ser joven, si eres rebelde, flojo y otras cosas que se le adjudican al joven. Puedes ser joven para ellos hasta la edad 
de 30 años si no has madurado o no te has casado.

L - Yo me caso y de repente me dicen: es que ya no eres joven, ya pasaste una etapa de tu vida, ya tienes cierta edad, entonces ya no eres joven. Esto es muy relativo, porque forma parte de tu identidad el ser joven. En las comunidades indígenas de repente te dicen: no pues, es que tú ya no eres joven, porque ya tienes esposo o esposa y ya tienes hijos. Pero igual tú quieres seguir siendo joven y automáticamente te dicen que ya no lo puedes ser.

C - Dentro de nuestra concepción, tu grupo familiar o tus redes de familia o paisanos, también ellos te consideran de esa manera. Cuando ya terminas tu soltería... L - Eres adulto cuando ya tienes hijos o pareja.

C - En parte ¿no?, porque igual si te casas aquí en la ciudad, te dirán que tú ya eres una madre, eres un padre, tienes que ser responsable y a la juventud se le adjudica irresponsabilidad.

G - ¿No será que precisamente por convención de los medios de comunicación nos queremos sentir jóvenes? Nuestros abuelitos y la gente grande nos decían: 'no, antes no nos faltaban al respeto, antes no eran así'. O sea, antes había un modo correcto de ser. Ellos dicen que con la televisión, con estas concepciones que nos han metido, las concepciones sobre la juventud, que nos dicen allá, son las que llegaron a meterse aquí; antes cómo un joven iba a decir: 'déjame decidir mi libertad', ¿cuál tu libertad? tú tienes que cumplir tu papel y punto, o sea, si te mandan a hacer esto, lo haces, eres respetuoso; o eres niño o eres un adulto. No hay una etapa intermedia donde les contestes a tus papás.

C - Lo que pasa es que ya no vives bien esas etapas, a lo mejor tus abuelos o tus papás si lo vivieron; cuando eran niños jugaban como niños y pensaban como niños, pasaron una edad de 12 a 18 años y entraron a una etapa de amigos o no sé cómo hayan vivido allá en su pueblo, pero lo vivieron; y después de eso buscaron establecer su vida tratando de encontrar a una pareja, que ese es el primordial del ser humano, dejar descendientes...

A - mujer: Me puedo juntar con gente de hasta 40 años, pero saber hasta qué distancia lo hago y tenerles un cierto respeto. Lo mismo pasa con los niños. De la misma manera, con los jóvenes de tu edad, porque sé que pensamientos tienen, que están sintiendo lo mismo y eso. Hablamos de la escuela, de los chavos o de muchas cosas, y es que hay factores que van variando, como jóvenes a veces tenemos muchos temas con los cuales te vas a identificar. Así como te estás identificando, vas a ver la actitud de aquella persona que realmente está siendo madura o cómo se está portando (Comunicación personal, 2006). 
La discusión arranca polarizada, por un lado, se presenta la visión indígena y por otro, opuesto, la occidental. Desde la primera, "ser joven" se define por "construcciones socioculturales" como la soltería, principio organizador de la diferencia. Desde la segunda, se da una definición "biológica" o "institucional" que toma la edad como principio organizador de la diferencia. Ambas perspectivas tienen un carácter normativo, pues prescriben modos específicos de ser joven establecidos por la sociedad adulta. Conforme avanza el diálogo, se suavizan las polarizaciones y se reconoce su compenetración: la visión institucional incorpora atributos socioculturales (imágenes juveniles de los medios de comunicación) y la visión indígena, criterios biológicos. Más adelante, critican la naturaleza prescriptiva y adultocéntrica de las visiones del "ser joven" y sostienen que hay maneras diferentes de vivir la juventud. Desde los jóvenes que definen su propia juventud se perfila tenuemente una postura: "ser joven" es una identidad cultural compartida entre jóvenes indígenas y no indígenas, la experiencia vital es el principio organizador de la diferencia con respecto a los adultos. La timidez con la que se plantea la definición está ligada con la novedad de la condición juvenil entre los participantes y el enfrentamiento conflictivo con las definiciones adultrocéntricas cuando intentan desplazarse de las convenciones de "los abuelitos o la gente grande".

\section{Ser indígena y ser migrante joven en la contemporaneidad}

Autoadscribirse como indígena en la ciudad es un asunto complicado para los jóvenes por la carga negativa y peyorativa del término. La abundante presencia indígena en la Ciudad de México no ha traído consigo una transformación de los modos racializados de clasificación social (Wallerstein; Balibar, 1988) que colocan a los indígenas en una posición inferior con respecto a los mestizos, y que niega su acceso pleno a la ciudadanía (Oemichen, 2003). Las jerarquías de clase instalan un código social que asocia al "indígena” con "gente ignorante", "que no sabe hablar español”, "sucio", "indigente" y "pobre”. Estas expresiones no son empleadas únicamente para distinguir entre mestizos e indígenas, estos últimos emplean términos sucedáneos cuando discriminan y califican negativamente a otros grupos étnicos que consideran inferiores. El discurso de los universitarios resaltó expresiones peyorativas que los juchitecos usan al referirse a los mixes, chontales y otros grupos étnicos.

En la ciudad, muchos jóvenes con orígenes étnicos tienden a disfrazar sino borrar los rastros de su indigeneidad por las prácticas discriminatorias de la violencia racista en la que se desenvuelven en muchos de los ámbitos de su vida cotidiana. 
Sin embargo, con las políticas positivas o afirmativas en el acceso a la educación y a otros programas que surgieron después de las reformas constitucionales de 1992 y 2001, muchos de ellos hacen visible su adscripción étnica, aunque para ello les sean exigidos una serie de trámites institucionales con los que puedan demostrar su pertenencia étnica y juvenil y acceder a ciertos beneficios. Muchos jóvenes de orígenes étnicos nacidos en la ciudad están "construyendo origen”, otros se amestizan. Unos y otros asumen compromisos distintos, unos el comunitario; otros el individualista. No todos asumen de igual manera adscribirse étnicamente. Para algunos, ser indígena era "igual de vulnerable que el ser de otra condición social”; otros la homologaban a adscripciones juveniles como ser "punketo", “darketo”, "roquero”, etc.”, reivindicando así otro aspecto de auto adscribirse indígena en la ciudad, "como ejercicio del derecho a la diferencia”.

El reciente fortalecimiento de la etnicidad en la ciudad está siendo protagonizado por los más jóvenes y es empujado por las generaciones étnicas que migraron antes a la ciudad. Éstas están construyendo mecanismos internos en sus organizaciones pluriétnicas para el "relevo generacional".

A partir de reconocer las múltiples identificaciones que los jóvenes indígenas experimentan en el mundo social, observé que la identidad étnica se convertía en uno de los "ropajes culturales" con que se puede "comunitariamente" afrontar el cotidiano en la ciudad. Este ropaje cultural no está dado (ni se da por sentado), se construye y se gana a través de la participación en proyectos (algunos inter) étnicos que coadyuvan con novedosas formas organizativas al reagrupamiento de la diversidad étnica migrante en la urbe. Algunos jóvenes estudiantes han ingresado a formar parte de organizaciones como la Asamblea de Migrantes Indígenas en la Ciudad de México que agrupa a una diversidad de etnias migrantes; y otros están formando nuevas organizaciones a partir de su condición juvenil, como el caso de la Asamblea Nacional de Jóvenes Indígenas, manifestando ser "herederos de la tradición” y su voluntad de "cohesionar a un movimiento indígena fragmentado y disperso" para caminar "unidos, compartiendo un mismo pensamiento, una misma visión”. Se trata en ambos casos de unirse en sus diferencias por la defensa, realización y ampliación de sus nuevos derechos, de revitalizar (y posibilitar con su escritura) el uso de las lenguas e ir encontrando en sus referentes de origen - en interacción con los contemporáneos - nuevas maneras de reconfigurarse en las ciudades y en los nuevos campos de acción en los que han ingresado.

Lo juvenil indígena se complejiza con la supuesta condición de migrante en la 
ciudad. Si bien, cualquier nacido fuera de la ciudad técnicamente puede considerarse un migrante, solo a los indígenas se les etiqueta socialmente como "migrantes”. La práctica es aparentemente inofensiva y permite a las instituciones gestionar información demográfica, mas no podemos ignorar su dimensión como estrategia de exclusión. En un recuento histórico de la exclusión indígena de la membresía urbana, Yuri Escalante (s/f) explica cómo la sociedad dominante ha creado la idea de que los indígenas pertenecen al medio rural y campesino, mientras que las ciudades son el espacio de lo cosmopolita, que asimila y elimina las diferencias culturales. Los jóvenes responden de distintas maneras a sus experiencias como migrantes. Algunos denunciaron que el término "migrante" es excluyente en el entorno de la competitividad laboral: "de entrada, se relaciona con una connotación negativa, peyorativa: migrante es como el que llega a Estados Unidos, que llega a ocupar espacios, a quitar trabajos" (Diario de campo, 2006). Otros comentaron que los hace sentirse "diferentes", "extranjeros" y en una posición de desventaja. Otros, rechazan esta asignación de migrantes y luchan por ser considerados como habitantes de la ciudad. Unos más, asumen su condición migrante y amplían su sentido mientras se desplazan entre territorios, así, se identifican como portadores de cambios sociales:

Es como que se adquieren dos nacionalidades, en mi caso, sé hablar el mixe y cuando fui niño adopté toda la cultura de origen, aunque también se lleva la otra parte de la nueva cultura. En estos tiempos de globalización yo soy un ciudadano del mundo $[\ldots]$ ¿qué es un ciudadano del mundo? Es valiente y es un hijo que aporta algo, puede enriquecer algo. Tanto como puede traer algo al medio en el que va a vivir, en el que va a convivir uno, dos, cinco o diez años; como también puede llevar algo al regresar a su comunidad, ya que vivió otras formas de convivencia, aprendió a vivir con ellas, otras reglas, otras personas (Diario de campo, comunicación personal, 2006).

Los comportamientos de los jóvenes indígenas en la ciudad están evidenciando: que ni la edad, ni la etnicidad, pueden ser concebidos más como atributos de los sujetos, sino como disyunciones que organizan las prácticas de los sujetos siempre entramados con otras segmentaciones como el género, la clase, la generación, consumo, en donde alguno de éstos, y por la situación que el actor esté experimentando en el contexto específico de sus interacciones, emerja como preponderante. Así en situación (en acto) se es o no joven, se es o no otomí o indígena, se es o no migrante. Estas prácticas revelan un "habitus 
reflexivo" (Lash, 2008) que filtra, sintetiza y elige juiciosamente, esto es, procesos de individuación en curso.

Para la generación de más edad, estos comportamientos y actitudes son percibidos como contradictorios; sin embargo, los jóvenes advierten que habitan un único mundo, que aunque muy complejo, es solo uno. También, los términos jóvenes, indígenas y migrantes son usados por los jóvenes de maneras diversas dependiendo de las situaciones en las que se encuentren, según los apoyos institucionales, los interlocutores con los que entran en relación o las posibilidades de acceso a ciertos recursos que podrían negociar con esos diferentes. Algunos investigadores que asumen la edad y la etnicidad como atributos, interpretan estas prácticas como utilitarias y oportunistas; otros, sostienen “que los jóvenes indígenas están perdiendo su identidad". Al contrario, tienen múltiples identificaciones: "vivo diferentes identidades, la de ser mixe, indígena, mujer, mexicana, estudiante, etc.” (Diario de campo, comunicación personal, 2006). Desde la perspectiva teórica de esta investigación, hablar tu lengua, ser indígena, estudiante universitario, líder de proyectos, son llaves de acceso étnico a la contemporaneidad y a la supervivencia de las etnias, en el sentido de su proyección al porvenir.

Esta investigación reveló el dinamismo y protagonismo de los jóvenes en los flujos migratorios y en las ciudades a las que arriban, el uso que hacen de las asignaciones identitarias étnicas esencializadas como recursos políticos en sus negociaciones con las instituciones para lograr más y mejores apoyos y derechos que les posibiliten reposicionarse de manera individual y comunitaria en la sociedad. Nos dicen: 1) de las salidas del sujeto indígena del lugar que la sociedad moderna del siglo XX le asignó - el campo, lo rural, la pobreza, lugares fijos y cerrados al mundo exterior - y de la emergencia de un sujeto étnico que comparte con nosotros su contemporaneidad; 2) del desvanecimiento de las fronteras o distinciones teóricas que colocaban de un lado a los indígenas (lo rural, el rito) y, de otro, a la sociedad moderna (el empleo, la educación, las TICs, "los otros") y la necesidad de reconocer políticamente el involucramiento activo de estos actores con el mundo contemporáneo.

Sostiene M. Abèles (2012) que durante más de un siglo la antropología ha puesto énfasis en lo que distingue a la cultura del observado y la del observador, acentuando la distancia con "el otro" que no es más que una forma de dominación. Esta investigación me hizo preguntar si era necesario seguir categorizando "al otro" como indígena - categoría creada en el siglo XX bajo el proyecto indigenista e inte- 
gracionista mexicano. Los criterios que sirvieron para la construcción y el reconocimiento diferenciado de los indígenas por parte de la antropología mexicana fueron diacríticos como la lengua, los rasgos fenotípicos o precolombinos, la poca fusión étnica y cultural, la organización social y religiosa como elementos constitutivos a su diferencia. Las prácticas y percepciones de los jóvenes étnicos en la ciudad desafían las condiciones de producción de la alteridad étnica en la antropología mexicana, el "alacronismo", esa manera de apartar al otro de nuestro tiempo, y proponen la co-pertenencia del investigador y de su interlocutor a la misma temporalidad.

Mi necesidad de construir conocimiento con y sobre los jóvenes indígenas en las ciudades me forzó a convertir en estratégica la referencia a su contemporaneidad. Los jóvenes con los que investigué están adscritos a diferentes clases sociales y etnias en la ciudad, así como a diferentes actividades y ocupaciones y abren la discusión sobre la complejidad de las interconexiones y flujos que construyen la diversidad cultural hoy, en la "que la noción de autenticidad pierde toda significación mientras se observan simultáneamente fenómenos de recomposición y fusión” (Abèles, 2012, p. 115).

\section{El reto de las nuevas metodologías en la antropología: para concluir}

Tiempo después de terminar esta investigación, conocí por primera vez algunos trabajos desarrollados bajo una novedosa propuesta epistemológica que asume que investigador e investigado pueden aportar lo que saben y conocen para producir conocimiento nuevo de forma conjunta. Se trata de construir conocimiento con el otro y no sobre el otro en un diálogo en el que el(la) investigador(a) debe abrir y crear las condiciones de igualdad con el otro necesarias para que ambos aporten lo que conocen y producir ambos conocimiento nuevo. Sarah Corona sostiene que ya no es posible llegar con los sujetos de investigación y creer que se les entiende para luego traducirlos a conceptos de una investigación dominante. La estrategia metodológica planteada por esta investigadora es conocida en ciertos ámbitos como metodología horizontal y dialógica. Esta propuesta me hace reflexionar sobre la investigación desarrollada y de alguna manera encontrar que realicé algunos pasos metodológicos en ese sentido. Considero haber abierto o creado condiciones de igualdad y horizontalidad necesarias, durante el tiempo de esta investigación, para que los jóvenes se sintieran en confianza y aportaran conocimiento nuevo sobre ellos mismos y sus entornos que luego plasmé en la representación etnográfica usando la propuesta Appadurai (2001) de "paisajes étnicos”- paisaje de personas y 
grupos en movimiento - siguiendo la máxima de Virilio (1997, p. 13) "un paisaje no tiene un sentido obligado, un punto de vista privilegiado; se orienta solamente por el derrotero de sus caminantes”.

Sí bien, conocí ese sujeto emergente precisamente porque posibilité la participación de los sujetos en su propia investigación y en el diseño de su propia juventud y etnicidad, no llevé a cabo la segunda parte de esta propuesta, "el juntos conocer para hacer algo nuevo. Crear. Producir algo diferente” (Corona, en Martínez, 2016). Esa intersección de saberes que puede producir conocimiento nuevo sobre nosotros y los otros en un solo mundo. Sigue siendo un reto para mí como investigadora.

Recebido: 30/04/2019

Aprovado: 28/08/2019

Maritza Urteaga Castro Pozo es Doctora en Ciencias Antropológicas por la UNAM, se desempeña como Profesora Investigadora del Posgrado en Antropología Social en la Escuela Nacional de Antropología e Historia (ENAH) en México, donde también dirige la línea de investigación "Jóvenes y sociedades contemporáneas”. Es miembro nivel II del Sistema Nacional de Investigadores y ha publicado varios libros, entre ellos: La construcción juvenil de la realidad. Jóvenes mexicanos contemporáneos (2011) y Juventudes contemporáneas.Visibilidad en el espacio urbano (con Edith Cortés y Margarita Salazar, 2015). ORCID iD: https://orcid.org/0000-0002-4163-083X. Contacto: maritzaurteaga@hotmail.com

\section{Notas}

1. Sobre la población indígena: sería muy sesgado inferir su participación en los censos con el indicador "hablante de lengua indígena" del INEGI. "La población con características indígenas del país ha sido estimada por expertos en cerca de 12, 707, 000 personas, si bien el XII Censo General de Población y Vivienda de 2000 registra un total de 6, 044, 547 personas de cinco años y más que hablan lengua indígena. La diferencia se explica porque un porcentaje importante de población indígena ha perdido el uso de su lengua; no obstante, ello no significa la pérdida de la identidad, de 
allí que en el censo se encuentre subregistrada esta población" (Vargas; Flores, 2002). La disputa por las cifras (cuántos son) forma parte del reconocimiento de los derechos étnicos.

2. La Alameda Central de la Ciudad de México es un parque público construido en el siglo XVI para embellecer la ciudad y habilitar un lugar de recreación, restringido a las clases altas. Durante los siglos XVII y XVIII el espacio fue objeto de abandono y varias remodelaciones. En el siglo XIX las obras de mantenimiento y mejoramiento de la favorecieron su constitución como un espacio de reunión popular. Desde entonces, la Alameda se vio transformada por la inserción de actividades y construcciones para el esparcimiento como kioscos, juegos infantiles, conciertos y venta ambulante. Actualmente, la Alameda es un espacio de recreación y reunión para familias, jóvenes, indígenas, trabajadoras domésticas, predicadores, ancianos y homosexuales, también es un lugar de pernocta de personas en situación de calle, ambulantes y drogadictos, y de trabajo para chichifos (sexoservidores discretos que son buscados por hombres adultos homosexuales), merolicos (vendedores callejeros), acróbatas y artistas callejeros (Servín, 2018).

3. La Alameda Central de la Ciudad de México es un parque público construido en el siglo XVI para embellecer la ciudad y habilitar un lugar de recreación, restringido a las clases altas. Durante los siglos XVII y XVIII el espacio fue objeto de abandono y varias remodelaciones. En el siglo XIX las obras de mantenimiento y mejoramiento de la favorecieron su constitución como un espacio de reunión popular. Desde entonces, la Alameda se vio transformada por la inserción de actividades y construcciones para el esparcimiento como kioscos, juegos infantiles, conciertos y venta ambulante. Actualmente, la Alameda es un espacio de recreación y reunión para familias, jóvenes, indígenas, trabajadoras domésticas, predicadores, ancianos y homosexuales, también es un lugar de pernocta de personas en situación de calle, ambulantes y drogadictos, y de trabajo para chichifos (sexoservidores discretos que son buscados por hombres adultos homosexuales), merolicos (vendedores callejeros), acróbatas y artistas callejeros (Servín, 2018).

4. La encuesta arrojó otros espacios públicos de la ciudad de México como lugares de encuentro entre jóvenes indígenas de reciente migración como el Bosque de Chapultepec, La Villa de la Virgen de Guadalupe, deportivos de varias delegaciones, el Parque de los Venados en la delegación Benito Juárez y otros más.

5. Abilio Vergara (2001) define el lugar como una configuración espacial y territorial con códigos axiológicos y formas de relacionalidad específicas; su singularidad está dada por el uso intensivo de un grupo o comunidad que le provee de sentido, lo instituye significativa y afectivamente de forma constante. Si bien los lugares son constituidos por una determinada comunidad, también tienen un poder constitutivo en ellas.

6. Sobre el peso demográfico de la población juvenil en México de acuerdo con los censos: hay un incremento en frecuencias absolutas. En 1990 se censan 23,898,078 jóvenes entre 15 y 29 años, y en 2000 asciende a 27,221,012. Pero con respecto al total de población, la tendencia es decreciente: el porcentaje de población juvenil entre 15 y 29 años en 1995 fue de 29.9\%, en 2000 de 28.5\%, 2005 de $27.1 \%$ y 2010 de $26.8 \%$ (INEGI, s/f).

7. La técnica de la bola de nieve (snowball sampling) es una técnica utilizada en la investigación cualitativa, sobre todo para la realización de entrevistas individuales. Una vez identificadas las primeras personas que serán entrevistadas, mediante estas se consiguen otros contactos, y así, hasta completar una cantidad de informantes necesaria sin que sea representativa. La ciudad de México es 
una megalópolis con población indígena muy dispersa en términos geográficos, una gran cantidad de la misma habita en zonas conurbadas a la Ciudad.

8. En la Delegación Cuauhtémoc, Ciudad de México.

9. El Molinito está ubicado en Naucalpan de Juárez, Estado de México, y es zona conurbana a la Ciudad de México.

10. Santo Domingo del Estado es un pueblo y agencia municipal habitado por indígenas triquis, ubicado en el municipio de Putla Villa de Guerrero, Estado de Oaxaca.

11. Nicolás Romero es uno de los 125 municipios del Estado de México y forma parte de la Zona Metropolitana del Valle de México, ubicada a $12 \mathrm{~km}$ de la Ciudad de México.

12. Toreo Cuatro Caminos estuvo ubicado en los límites de la Alcaldía Miguel Hidalgo, Ciudad de México y el municipio de Naucalpan de Juárez, Estado de México. Fungió entre 1947 y 2008 como Plaza de Toros, luego como centro de espectáculos, reuniones y centro deportivo.

13. Según la encuesta aplicada a 4,291 indígenas mazahuas, otomíes, zapotecos, mayas y triquis en las ciudades de México, Minatitlán y Cancún, el porcentaje de mujeres indígenas que trabajan en la ciudad, 45.7\%, es mayor al porcentaje nacional de población femenina ocupada, 31.3\% (XII Censo General de Población y Vivienda, 2000). La mayoría de las mujeres indígenas se ocupa en el sector informal, pero a diferencia de los hombres, las jóvenes tienen experiencias menos diversas. En la ciudad hay alta demanda de trabajo doméstico y la imagen de la mujer indígena se estereotipa en la de empleada doméstica, lo cual da lugar a que muchas tengan esta actividad como única experiencia laboral (Vargas; Flores, 2002).

\section{Referencias}

ABELÈS, Marc. 2012. Antropología de la globalización. Argentina: Ediciones del Sol.

AGIER, Michel. 2015. Zonas de frontera: la antropología frente a la trampa identitaria. Rosario: UNR Editora.

AMI-ASAMBLEA DE MIGRANTES INDÍGENAS DE LA CIUDAD DE MÉXICO. 2006a. Asamblea de Migrantes Indígenas. México. Disponible en: http: / / www.indigenasdf.org. mx/. Acceso en: 03 mayo 2006.

AMI-ASAMBLEA DE MIGRANTES INDÍGENAS DE LA CIUDAD DE MÉXICO. 2006b. Sistema de cargo de los pueblos indígenas. México. Disponible en: http: / /www.indigenasdf.org. mx/. Acceso en: 03 mayo 2006.

ANGUIANO, Mariana. 2002. “Jóvenes huicholes migrantes de Nayarit”. Diario de Campo, Suplemento 23, p. 37-50.

APPADURAI, Arjun. 2001. La modernidad desbordada: dimensiones culturales de la globalización. Buenos Aires: Trilce/FCE.

BHABHA, Homi. 2002. El lugar de la cultura. Buenos Aires: Manantial.

BOURDIEU, Pierre. 2012. Bosquejo de una teoría de la práctica. Buenos Aires: Prometeo Libros.

CAPUTO, Virginia. 1995. “Anthropology's silent 'others'. A consideration of some conceptual and methodological issues for the study of youth and children's cultures”. En: AMIT-TALAI, Vered; WULFF, Helena (Eds.). Youth cultures: a cross-cultural perspective. Londres: Routledge. p. 19-42. 
ESCALANTE, Yuri. S/f. Proyecto de Investigación "La exclusión indígena de la membresía urbana”. México. Disponible en: http://www.indigenasdf.org.mx/convivencia.php. Acceso en: 06 dic. 2014.

FEIXA, Carles. 1998. El reloj de arena: culturas juveniles en México. México: Causa Joven/SEP.

FERNÁNDEZ PONCELA, Anna. 2003. La construcción social de la juventud. En Cultura política y jóvenes en el umbral del nuevo milenio. México: IMJ/IFE/SEP.

GARCÍA, Ariel. 2003. Juventud indígena en Coyutla: construcción de identidades en el espacio rural. Tesis (Maestría en Antropología Social), Centro de Investigaciones y Estudios Superiores en Antropología Social, México.

HALL, Stanley. 1905. Adolescence: its psychology and its relations to physiology, anthropology, sociology, sex, crime, religion and education. New York: Appleton Century Crofts.

IMJ-INSTITUTO MEXICANO DE LA JUVENTUD. 2002. Encuesta Nacional de Juventud 2000: jóvenes mexicanos del siglo XXI. México: IMJ y SEP.

INEGI-INSTITUTO NACIONAL DE ESTADÍSTICA, GEOGRAFÍA E INFORMÁTICA. S/f. XII Censos y Conteos de Población y Vivienda. Disponible en: https://www.inegi.org.mx/ programas/ ccpv/2000/. Acceso en: 30 jun. 2019.

JAMES, Allison. 1995. "Talking of children and youth. language, socialization and culture". En: AMIT-TALAI, Vered; WULFF, Helena (Eds.). Youth cultures: a cross-cultural perspective. Londres: Routledge. p. 43-62.

LASH, Scott. 2008. "La reflexividad y sus dobles: estructura, estética y comunidad”. En: BECK, Ulrich; GIDDENS, Anthony; LASH, Scott. Modernización reflexiva: política, tradición y estética en el orden social moderno. Madrid: Alianza. p. 137-208.

MARCUS, George. 2001. "Etnografía en/del sistema mundo: el surgimiento de la etnografía multilocal”. Alteridades, v. 11, n. 22, p. 111-127.

MARTÍNEZ, Miguel Angel; GARCÍA, Juan Enrique; FERNÁNDEZ, Patricia. 2003. Indígenas en zonas metropolitanas. En: CONAPO. La situación demográfica de México. México: CONAPO. p. 155-164.

MARTÍNEZ, Regina; ROJAS, Angélica. 2005. “Jóvenes indígenas en la escuela: la negociación de las identidades en nuevos espacios sociales”. Antropologías y estudios de la ciudad, v. 1, n. 1, p. 105-122. MARTÍNEZ, Regina. 2002. "La invención de la adolescencia: las otomíes urbanas en Guadalajara”. Diario de Campo, Suplemento, n. 23, p. 23-36.

MARTÍNEZ, Rodrigo. 2016. "La comunicación produce cambio social si respeta múltiples razones. Entrevista con Sarah Corona Berkin”. En: CORNEJO, Inés (Coord.). Juventud rural y migración mayahablante. México: UAM. p. 205-209.

MEAD, Margaret. 1979. Adolescencia, sexo y cultura en Samoa. Barcelona: Laia.

MENESES, Jorge. 2002. Juventud, sexualidad y cortejo en una comunidad indígena de Oaxaca. Tesis (Licenciatura en Antropología Social), Escuela Nacional de Antropología e Historia - ENAH, México.

MORA, Teresa; DURÁN, Rocío; CORONA, Laura; VEGA, Leonardo. 2004. "La etnografía de los grupos originarios y los inmigrantes indígenas de la ciudad de México”. En:YANEZ, Pablo; 
MOLINA, Virginia; GONZÁLEZ, Oscar (Coords.). Ciudad, Pueblos Indígenas y Etnicidad. México: UACM. p. 225-248.

OEMICHEN, Cristina. 2003. La multiculturalidad de la ciudad de México y los derechos indígenas. México. Disponible en: http://www.equidad.df.gob.mx/indigenas/seminario/ 03_mar_segunda_oemichen.html. Acceso en: 08 mayo 2009.

ORTEGA, Zózimo. 2001. "El derecho triqui de Xuman Li en el medio urbano”. Revista Crítica Jurídica [online], n. 18. Disponible en: http://www.triquis.org/html/modues.php. Acceso en: 27 mayo 2005.

ORTIZ, Celso. 2002. Las venas del campo: las tagotg (las jóvenes) y los chogotg (los jóvenes) en la comunidad de Pajapan, Veracruz, y sus estrategias de vida. Tesis (Licenciatura en Antropología Social), Escuela Nacional de Antropología e Historia - ENAH, México.

PACHECO, Lourdes. 1997. "La doble cotidianeidad de los huicholes jóvenes. Aportaciones sobre la identidad juvenil desde la etnografía”. Jóvenes - Revista de Estudios sobre Juventud, n. 4, p. 100-112. PÉREZ RUIZ, Maya. 2002a. "Del comunalismo a las megaciudades: el nuevo rostro de los indígenas urbanos”. En: DE LA PEÑA, Guillermo; VÁZQUEZ, Luis (Coords.). La antropología sociocultural en el México del milenio: búsquedas, encuentros, transiciones. México: FCE/INI/CNCA. p. 295-340.

PÉREZ RUIZ, Maya. 2002b. “Jóvenes indígenas y su migración a las ciudades”. Diario de Campo, Suplemento, n. 23, p. 7-20.

PÉREZ RUIZ, Maya. 2011. "Retos para la investigación de los jóvenes indígenas”. Alteridades, v. 21, n. 42, p. 65-75.

ROSALDO, Renato. 1991. Cultura y verdad. México: Grijalbo/CNCA.

SERVÍN, Juan Manuel. 2018. Nada que perdonar: crónicas facinerosas. México: Random House.

URTEAGA, Maritza; GARCÍA, Luis. 2015. “Juventudes étnicas contemporáneas en Latinoamérica”. Cuicuilco, v. 26, n. 62, p. 7-35.

URTEAGA, Maritza; GARCÍA, Luis. 2016. "Rutas para aproximarnos a la disputa por la interculturalidad desde la educación superior y los jóvenes indígenas en América Latina”. En: DI CAUDO, María; OSPINA, María; LLANOS, Daniel (Coords.). Interculturalidad y Educación Superior desde el Sur: contextos, experiencias y voces. Ecuador: Abya-Yala; Universidad Politécnica Salesiana; Universidad de Manizales; CINDE; CLACSO. p. 7-28.

URTEAGA, Maritza. 2008a. “Jóvenes e indios en el México contemporáneo”. Revista Latinoamericana de Ciencias Sociales, Niñez y Juventud, v. 6, n. 2, p. 667-708.

URTEAGA, Maritza. 2008b. "Lo juvenil en lo étnico. Migración juvenil indígena en la sociedad contemporánea mexicana”. Revista Ponto-e-Vírgula, n. 4, p. 261-275.

URTEAGA, Maritza. 2011. "Retos contemporáneos en los estudios sobre juventud”. Alteridades, v. 21, n. 42, p. 13-32.

URTEAGA, Maritza. 2016. "Jóvenes indígenas: etnias del desplazamiento y zonas fronterizas en la Ciudad de México”. En: FEIXA, Carles; OLIART, Patricia (Coords.). Juvenopedia: mapeo de las juventudes latinoamericanas. España: NED Ediciones; Biblioteca de Infancia y Juventud. p. 159184. 
VALENCIA ROJAS, Alberto J. 2000. La migración indígena a las ciudades. México: INI-PNUD.

VARGAS, Patricia; FLORES, Julia. 2002. "Los indígenas en ciudades de México: el caso de los mazahuas, otomíes, triquis, zapotecos y mayas”. Población, n. 34, p. 235-257.

VERGARA, Abilio. 2001. "El lugar antropológico: una introducción”. En: AGUILAR, Miguel Angel; SEVILLA, Amparo; VERGARA, Abilio (Coords.). La ciudad desde sus lugares: 13 ventanas etnográficas para una metrópoli. México: UAM/Porrúa/CNCA. p. 5-33.

VIRILIO, Paul. 1997. Un paisaje de acontecimientos. Buenos Aires: Paidós.

WALLERSTEIN, Immanuel; BALIBAR, Étienne. 1988. Raza, nación y clase. Madrid: IEPALA. 
Resumen: El artículo examina las estrategias etnográficas que he implementado a lo largo de mi experiencia investigativa con jóvenes indígenas en la Ciudad de México. Los hallazgos del trabajo de campo ofrecen una representación de los paisajes étnicos de estos sujetos emergentes y de cómo articulan su condición juvenil, étnica y migrante. La observación de sus interacciones en tres escenarios socioculturales hizo evidente sus desplazamientos contemporáneos y la disolución de fronteras que enmarcaron a las investigaciones anteriores sobre población indígena. A la luz de estos descubrimientos, reflexiono sobre los desafíos epistémicos que nos exige la adopción de metodologías horizontales que prioricen las prácticas simbólicas a través de las cuales la sociedad es experimentada por la gente joven.

Palabras-claves: jóvenes indígenas de México; migración a las ciudades; alteridad y etnicidad contemporáneas; metodologías horizontales; zonas de frontera.
Abstract: This article examines the ethnographic strategies that I have implemented throughout my research experience with indigenous youths in Mexico City. The findings of the fieldwork offer a representation of the ethnic landscapes of these emerging subjects and how they articulate their youth, ethnicity and migrant status. The observation of their interactions in three sociocultural scenarios highlight their contemporary displacements and the dissolution of boundaries that framed the previous research on indigenous population. In view of these discoveries, I reflect on the epistemic challenges involved in adopting horizontal methodologies that prioritize the symbolic practices through which society is experienced by young people.

Keywords: indigenous young from México, migration to the city; contemporary alterity and ethnicity; horizontal methodologies; border zones. 